\title{
$\begin{array}{ll}\text { Research Square } & \begin{array}{l}\text { Preprints are preliminary reports that have not undergone peer review. } \\ \text { They should not be considered conclusive, used to inform clinical practice, } \\ \text { or referenced by the media as validated information. }\end{array}\end{array}$
}

\section{The impact of government subsidy programs on equity in health financing}

Yousef Mohammadzadeh ( $\nabla$ yo.mohammadzadeh@urmia.ac.ir )

Urmia University https://orcid.org/0000-0002-4364-5832

Jafar Yahyavi Dizaj

Tehran University of Medical Sciences

Ali Mohammad Mosadeghrad

Tehran University of Medical Sciences

Ali Kazemi

Kermanshah University of Medical Sciences

Hasan Yusefzadeh

Urmia University of Medical Sciences

Research article

Keywords: Health System Evolution Plan, Justice in the Healthcare System, Fair Financial Contribution Index (FFCI), targeted subsidy plan

Posted Date: October 8th, 2020

DOI: https://doi.org/10.21203/rs.3.rs-87034/v1

License: @ (i) This work is licensed under a Creative Commons Attribution 4.0 International License. Read Full License 


\section{Abstract}

Background: Iran government launched the targeted subsidy plan (TSP) in December 2011 to reduce inequality and poverty. In addition, Health Transformation Plan (HTP) was implemented in ministry of health to reduce people out of pocket payment. This study aimed to examine the impact of these two government subsidy programs on equity in health financing.

Method: In this longitudinal study, data on 413,201 households were collected using household surveys during 11 years (2007-2017). The Fairness in Financial Contribution (FFCI) index and Catastrophic Health Expenditures (CHE) index were calculated.Also Logistic regression model was performed by the applied software of Stata V.14 to examine the effects of TSP and HTP policies and other socioeconomic characteristics of households on their exposure to CHE.

Results: The FFC index was 0.829 and 0.830 respectively in 2007 and 2017 . The trend analysis did not show significant changes in FFC index between 2007 and 2017. TSP and HTP implementation die not reduce households' exposure to CHE significantly. Crowded households with more elder people, belonging to low income deciles, without houses, living in rural areas and deprived provinces, are more likely to be at risk of $\mathrm{CHE}$. Health insurance coverage did not protect households from CHE. High educated and employed households were exposed to less CHE.

Conclusion: The government subsidy programs have not been effective in improving FFC and reducing $\mathrm{CHE}$ indices. None of them has been able to realize the goal of the $6^{\text {th }}$ National Development Plan of reducing $\mathrm{CHE}$ to $1 \%$. The government should devise support packages for target household (households with more elderly people, lower incomes, without private house, crowded, rural and inhabited in deprived provinces), so they can protect households against CHE. Modifying and improving the quality of insurance coverage is strongly recommended due to its inefficiency.

\section{Background}

The health system has important role in changing the health status of individuals; this role is played in the form of the provision of preventive, therapeutic and sanitary services(Xu, 2005). In fact, the acceptance of health as all individuals' right, which should be achieved at the highest level, makes governments obliged and committed to the treatment and prevention of illnesses so that they make all their efforts to create a situation where access to the health services is available to all people(Leary, 1994 and Kirby, 1999). Measures like granting subsidies, reducing inequality, and observing justice in delivering the health services(Murray et al, 2000), as well as fair financing can play an important role in improving the performance of the health system in providing the best quality services(Chen et al. 2014). According to the World Health Organization (WHO), the statement that "you get what you pay for" refers to the same concept of justice in the market transactions; while in the health system, providing health services as much as people's paying does not mean the concept of justice, and this market is different from the other conventional markets. In other words, people should have access to the health services regardless of their financial and economic status so as to continue their lives and maintain the mental and physical health standards, and lack of purchasing power should not prevent them from receiving services. This is because, firstly, health care is costly and expensive on its own; and secondly, the need for health services is unpredictable. Therefore, health system financing should be fair and in such a way that people do not face catastrophic expenditures when they need health services. Individuals should consider a percentage of their household income as a payment for receiving these health services; these payments may pose catastrophic costs to some households and bring them below the poverty line. According to WHO, households face catastrophic health expenditures when their health care cost equals or exceeds $40 \%$ of the total household capacity. As a result, these households may discontinue receiving health promotion services and prefer to tolerate illnesses, or they may disregard their basic needs such as education, clothing, etc $(\mathrm{Xu}, 2005)$.Catastrophic payments are very common in 
the developing countries with the moderate level of income and low income countries(Xu et al. 2003). Given the vital role of financing in the health system, fair financial contribution has become as one of the most important goals and concerns of the health systems(Murry, 2000). In addition, people's access to health care, inequality in responsiveness, and inequality in health care are largely influenced by the health system financing.

The Islamic Republic of Iran is a middle-income country with a population of about 78 million, with an annual population growth of $1.28 \%$, and a median age of 29 years. The gross national income per capita is (PPP int.) $\$ 17,400$. Seventy-two percent of the population live in urban areas(Group WB, 2016).

The Iranian healthcare system consists of public, private, and non-government organization (NGO)-funded healthcare. The Ministry of Health and Medical Education (MOHME) is responsible for policy-making, financing, planning, and controlling the health sector at the national level. At the provincial level, medical universities are responsible for providing both medical education and healthcare services. The district health network provides primary healthcare (PHC) services free of charge, and the hospital network delivers secondary and tertiary services(Mosadeghrad, 2014).

Government general revenues (e.g., taxes), public and private health insurance premiums, and individuals' out-of-pocket (OOP) payments are the main sources of financing health systems. The health financing system in Iran is highly regressive, fragmented, inefficient, and inequitable. Formal workers and their dependents are insured by the Social Security Organization (SSO), and members of the military and their dependents are covered through the Armed Forces Medical Service Organization (AFMSO). The remainder of the population is eligible to enroll in the Iran Health Insurance Organization (IHIO), which covers government public sector employees, rural households, the self-employed, clerics, students, and so on(Mosadeghrad, 2014).

Fair health system financing influence access and equity in the health system. Fair financial contribution is an important goal of the health system. Households' contributions in financing health expenditures determines the fairness of health system financing. Fair financial contribution (FFC) and catastrophic health expenditures (CHE) are example of indicators used for calculating equity in financing the health system. Iran devoted $6.6 \%$ of its gross domestic product to total health spending (1,218 PPP int. \$ per person) in 2012. The private expenditure on health as \% of total expenditure on health was $59.6 \%$ of which $88 \%$ was out of pocket(WHO, 2015).

Iran has made good progress in improving population health outcomes during the last three decades. Communicable diseases are well controlled; however, the country faces a burden of non-communicable diseases in addition to an increase in physical accidents and injuries due to the growth of urbanization and industrialization. The Iranian health system still faces a number of challenges when it comes to access, equity, quality, and efficiency. As a result, a number of healthcare reforms and initiatives have been implemented to enhance the referral system, increase capacity for training healthcare personnel, expand access to healthcare services, reduce inequities, and promote quality of healthcare services.

The parliament approved the Targeted Subsidies Plan (TSP) in 2010 and asked government to replace subsidies on energy and food with targeted social assistance. The removal of subsidies resulted in an increase of about $21 \%$ in prices (Enami et al, 2019). The amount of the universal cash transfer was 455,000 Rials (approximately \$ 41 in 2011 and $\$ 10$ in 2017) and remained the same over these 6 years. The government was also asked to use the freed funds for expanding social insurance, providing healthcare services, promoting community health, and covering sever ill patients' treatment and medicines. TSP was part of a broader Iranian economic reform plan based on the country's five year economic development plan. The government implemented the plan in 2011.

Spending on TSP exceeded the additional revenue generated from the increase in the prices of previously subsidized energy goods in large part because energy consumption was lower without the subsidies, but also because of the 
reduction in international oil prices(Salehi-Isfahani et al, 2016). In the first eighteen months of this reform, spending on TSP was almost twice the amount of the increase in government revenue that resulted from eliminating the energy subsidies(Enami et al, 2019). Thus, in 2014, the government decided to stop paying the top $20 \%$ of rich households the direct cash due to the budget limit.

Later on, the ministry of health and medical education implemented a series of reforms, called the Health Transformation Plan (HTP) to expand access to healthcare services, promote equity, reduce the catastrophic and impoverishing OOP payments, and improve the quality of healthcare services. The HTP was mainly focused on three departments of the MOHME (i.e., curative care, health, and education). Accordingly, all uninsured people were encouraged to register in the IHIO. All of the MOHME affiliated hospitals (561 out of the total 878 hospitals) should provide all necessary inpatient services. Patients' OOP payments at these hospitals should be less than $10 \%$ of the total medical expenditure. The national tariff for medical services was increased in October 2014 to encourage medical consultants to work full time in public hospitals and provide high-quality services, persuade medical doctors to stay in deprived areas, and reduce informal and illegal payments. The major source of the HTP funding was a raise in the MOHME budget comprising 1\% the value-added tax (VAT) and 10\% of freed subsidies(NIHR, 2016).

It is necessary to measure the effectiveness of these two government subsidy programs. Hence, the aim of this study was to examine the effect of TSP and HTP subsidy programs on equity of financing healthcare services in Iran.

\section{Method}

The data of this retrospective and descriptive study obtained from the annual survey of household income and expenditure conducted by Iran Statistical Center. The statistical population of the study consisted of all Iranian households. The randomized three-stage cluster sampling method was used for selecting samples (Naghdi et al, 2013). The "Household Income and Expenditure Survey" questionnaires were completed by interviewing the head of the households. The questionnaire covered questions about the social characteristics of the household members, household properties, food and non-food expenditures, and household income. Access 2013, Excel 2013 and STATA, v.12 were used to organize and analyze data. A total of 413,201 households from 2007 to 2017 (including 210,019 rural and 203,182 urban households) participated in this study. Table 1 shows the sample size for each year.

Table 1

The survey sample size (2007-2017)

\begin{tabular}{|llllllllllll|}
\hline $\begin{array}{l}\text { Year } \\
\text { Sample }\end{array}$ & 2007 & 2008 & 2009 & 2010 & 2011 & 2012 & 2013 & 2014 & 2015 & 2016 & 2017 \\
\hline Rural & 16266 & 19708 & 18204 & 19585 & 19787 & 19658 & 19437 & 19391 & 19382 & 19340 & 19261 \\
\hline Urban & 15019 & 19382 & 18666 & 18702 & 18728 & 18536 & 18881 & 18886 & 18872 & 18809 & 18701 \\
\hline Total & 31285 & 39090 & 36870 & 38287 & 38515 & 38194 & 38318 & 38277 & 38254 & 38149 & 37962 \\
\hline
\end{tabular}

In this study Fair Financial Contribution (FFC) index and Catastrophic Health Expenditures (CHE) index were calculated for measuring equity in health care financing. The FFC index is an indicator of financial equity which varies between 0 and 1; the fairer the health financing system, the closer is the FFC index to 1. In fact, mode 1 is the ideal state of FFC index in the health system (WHO, 2000). The World Health Organization formula was used for calculating FFC index in the health system(Murray et al, 2000). 
$F F C I=1-\sqrt[3]{\frac{\sum_{h=1}^{n} w_{h} / \text { oopctp }_{h}-\text { oopctp }_{0} / \beta^{3}}{\sum w_{h}}}$

Where $\mathrm{W}_{\mathrm{h}}$ is the household weighting variable when sampling with the actual population ratio is different in the rural and urban areas ( $h$ : the household identification code); OOPCTP $\left(\mathrm{OOP}_{h} / \mathrm{CTP}_{\mathrm{h}}\right)$ is the household's out of pocket

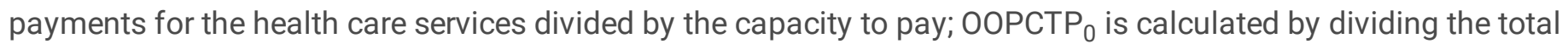
household health expenditure by the total capacity to pay. The CHE index was set at $40 \%$ or higher of the household capacity to pay $(\mathrm{Xu}, 2005)$. If households spend more than $40 \%$ of their capacity for the healthcare services, they suffer from CHE (Murray et al, 2003).

The Logit model was used to examine the effect of economic and social variables such as gender, age, place of residence, employment, level of education, etc. on the probability of households being exposed to CHE. Given the nature of the Logit models and the data used in this study, the final model can be presented as follows:

Cata $=\beta_{1} T S P+\beta_{2}$ Insurance $+\beta_{3}$ HTP $+\beta_{4}$ Size $+\beta_{5}$ Develop $+\beta_{6} R \_U+\beta_{7}$ Inum $+\beta_{8}$ Empnum $+\beta_{9}$ Decinc $+\beta_{10}$ Housing + $\beta_{11}$ Elder

\section{Results}

The FFC index was 0.829 and 0.830 respectively in 2007 and 2017 . The trend analysis does not show significant changes in FFC index between 2007 and 2017. The mean of FFC index was 0.815 for years 2007-2010 and 0.833 for years 2012-2017. There was no positive changes in the index in FFC index between 2014 and 2017, the years after HTP implementation. The TSP increased FFC by $9.6 \%$ (from 0.781 in 2010 to 0.856 in 2011) and the HTP increased it by $0.5 \%$. However, they were not successful in maintaining the improvement (Table 2 ).

Table 2

Distribution of the FFC index in the healthcare sector between 2007 and 2017

\begin{tabular}{|lccccccccccc|}
\hline $\begin{array}{l}\text { Area of } \\
\text { residence }\end{array}$ & $\mathbf{2 0 0 7}$ & $\mathbf{2 0 0 8}$ & $\mathbf{2 0 0 9}$ & $\mathbf{2 0 1 0}$ & $\mathbf{2 0 1 1}$ & $\mathbf{2 0 1 2}$ & $\mathbf{2 0 1 3}$ & $\mathbf{2 0 1 4}$ & $\mathbf{2 0 1 5}$ & $\mathbf{2 0 1 6}$ & $\mathbf{2 0 1 7}$ \\
\hline Rural & 0.817 & 0.820 & 0.802 & 0.785 & 0.846 & 0.838 & 0.814 & 0.821 & 0.821 & 0.82 & 0.820 \\
\hline Urban & 0.841 & 0.842 & 0.835 & 0.778 & 0.866 & 0.863 & 0.841 & 0.841 & 0.842 & 0.84 & 0.840 \\
\hline Total & 0.829 & 0.831 & 0.818 & 0.781 & 0.856 & 0.850 & 0.827 & 0.831 & 0.831 & 0.830 & 0.830 \\
\hline
\end{tabular}

As it is shown in Table 3, about 2.5\% of households suffered from CHE in 2007, the figure has increased to $3.3 \%$ in 2010 , then dropped to $1.8 \%$ in 2011 . Then, it experienced a raising trend and reached $3.65 \%$ in 2017 . The mean of $\mathrm{CHE}$ index was $2.9 \%$ for years $2007-2010$ and $3.2 \%$ for years $2012-2017$. 
Table 3

Distribution of households suffering CHE between 2007 and 2017

\begin{tabular}{|llll|}
\hline Area of residence & Rural & Urban & Total \\
\hline 2007 & Number(Percentage) & Number(Percentage) & Number(Percentage) \\
\hline 2008 & $494(\% 3)$ & $305(\% 2)$ & $798(\% 2.5)$ \\
\hline 2009 & $663(\% 3.3)$ & $418(\% 2.1)$ & $1081(\% 2.7)$ \\
\hline 2010 & $660(\% 3.6)$ & $469(\% 2.5)$ & $1129(\% 3)$ \\
\hline 2011 & $762(\% 3.8)$ & $527(\% 2.8)$ & $1289(\% 3.3)$ \\
\hline 2012 & $467(\% 2.3)$ & $246(\% 1.3)$ & $713(\% 1.8)$ \\
\hline 2013 & $481(\% 2.4)$ & $271(\% 1.4)$ & $752(\% 1.9)$ \\
\hline 2014 & $840(\% 4.3)$ & $537(\% 2.8)$ & $1377(\% 3.5)$ \\
\hline 2015 & $859(\% 4.4)$ & $510(\% 2.7)$ & $1369(\% 3.5)$ \\
\hline 2016 & $824(\% 4.2)$ & $511(\% 2.7)$ & $1335(\% 3.4)$ \\
\hline 2017 & $815(\% 4.2)$ & $500(\% 2.7)$ & $1315(\% 3.45)$ \\
\hline
\end{tabular}

Based on the results of the logit model estimation, TSP and HTP implementation not only reduce households' exposure to $\mathrm{CHE}$, they also caused numerous economic problems, which increased the likelihood of households' exposure to CHE. The results of model estimation are reported in Table 4 below. The results also show that crowded households with more elder people, belonging to low income deciles, without houses, living in rural areas and deprived provinces, are more likely to be at risk of $\mathrm{CHE}$. Health insurance coverage did not protect households from $\mathrm{CHE}$. High educated and employed households were exposed to less CHE. Households living in less developed provinces were facing more $\mathrm{CHE}$. One of the noticeable results of this study is the inefficiency of health insurance plans in protecting households against $\mathrm{CHE}$. Health insurance companies have not been able to reduce the likelihood of household exposure to $\mathrm{CHE}$. 
Table 4

Estimation of logit regression model of factors influencing CHE for the study period (20072017)

\begin{tabular}{|c|c|c|c|}
\hline Variable & Odds ratio & Z Statistical & p-value \\
\hline \multicolumn{4}{|l|}{ TSP } \\
\hline years of receiving subsidy for Households & Basic variable & & \\
\hline years of non-receiving subsidy by & $1.10(1.05-1.15)$ & 4.08 & $0.001>$ \\
\hline \multicolumn{4}{|l|}{ Insurance } \\
\hline Households without health insurance & Basic variable & & \\
\hline Households with medical insurance & $1.11(1.05-1.14)$ & 4.48 & $0.001>$ \\
\hline \multicolumn{4}{|l|}{ HTP } \\
\hline years before the plan & Basic variable & & \\
\hline years after the implementation of the plan & $1.11(1.06-1.16)$ & 4.19 & $0.001>$ \\
\hline size & $0.97(0.96-0.99)$ & -3.85 & $0.001>$ \\
\hline \multicolumn{4}{|l|}{ Developmental } \\
\hline Households living in deprived provinces & Basic variable & & \\
\hline Households living in semi-developed provinces & $0.95(0.90-0.99)$ & -2.46 & $0.014>$ \\
\hline Households in developed provinces & $0.9(0.86-0.94)$ & -4.67 & $0.001>$ \\
\hline \multicolumn{4}{|l|}{ R_U } \\
\hline Rural Households & Basic variable & & \\
\hline urban Households & $0.69(0.66-0.72)$ & -18.11 & $0.001>$ \\
\hline Literate-number & $0.96(0.93-.99)$ & -2.28 & $0.023>$ \\
\hline \multicolumn{4}{|l|}{ Empnum } \\
\hline Households without any employed & Basic variable & & \\
\hline Households with 1 employed person & $0.70(0.67-0.74)$ & -14.70 & $0.001>$ \\
\hline Households with 2 or more employed & $0.66(0.62-0.71)$ & -12.76 & 0.000 \\
\hline Decinc & $0.96(0.95-0.96)$ & -11.98 & $0.001>$ \\
\hline \multicolumn{4}{|l|}{ Housing } \\
\hline Households without a private house & Basic variable & & \\
\hline Households owning a private house & $0.92(0.88-0.96)$ & -3.44 & $0.001>$ \\
\hline \multicolumn{4}{|l|}{ Elder } \\
\hline Households without elderly & Basic variable & & \\
\hline Households of one elder & $1.59(1.51-1.67)$ & 18.58 & $0.001>$ \\
\hline
\end{tabular}




\begin{tabular}{|llll|}
\hline Variable & Odds ratio & Z Statistical & p-value \\
\hline Households with 2 or more elderly & $2.21(2.08-2.35)$ & 25.02 & $0.001>$ \\
\hline cons _ & $0.06(0.06-0.06)$ & -71.37 & $0.001>$ \\
\hline Log likelihood= -54386.338 & & & \\
\hline
\end{tabular}

\section{Discussion}

Iran government launched the Targeted Subsidy Plan (TSP) in December 2011 to reduce inequality and poverty. In addition, Health Transformation Plan (HTP) was implemented in ministry of health to reduce people out of pocket payment. The study aimed to examine the impact of TSP and HTP on equity in health financing. Relatively significant cash became available for households by introduction of TSP, and as a result, FFC index was improved and the CHE index was reduced. However, over time, the harmful effects of the distribution of money and the growth of liquidity became apparent, and inflation and poverty increased sharply. The TSP increased the inflation rate and as a result restricted the household's choices and decreased their purchasing power.

Our study found that the FFC index was improved and the CHE index was reduced up to one year after TSP implementation and after then, these indices were deteriorated. Salehi-Isfahani et al. (2015) looking at the impact of TSP three months after its implementation found that TSP reduced inequality and poverty. Similarly, Enami et al. (2019) reported a reduction in inequality and poverty one year after its introduction.

The accurate analysis of the justice index and the survey of households faced with CHE is not possible without identifying target groups and households. Therefore, it is necessary to identify households with a higher probability of Catastrophic Health Expenditure than others, according to their economic and social characteristics as far as possible. The socioeconomic characteristics of CHE households are described in detail in this study.

Considering that people over 65 are considered vulnerable and exposed to high costs of treatment, their presence in households has a positive and significant effect on the bearing catastrophic health expenditures. And as the number of elderly people in households is higher, households are more likely to face CHE. The study by Ma et al (2019), Pal (2012), and Marlis et al (2006), also confirms the result. Some studies have also found it effective for the household to face catastrophic expenditure(Wyszewianski, 1986; Hajizadeh and Nghiem, 2011). This variable was significant and positive in both models at level $99 \%$, which means that an increase in the elderly population in the household increases the probability of suffering from catastrophic health expenditures. The odds of this variable equal 1/59 for the presence of an aged person in the family and 2/21 for the presence more number of aged persons. The household with one elderly and households with 2 elderly and above that, respectively 1.59, 2.21 times more than the non-elderly households exposed to CHE. Due to the aging population in Iran, policymakers should pay particular attention to this issue.

The risk of exposure to catastrophic health expenditures in rural areas is higher urban than areas, which is significant at $99 \%$; rural households are more likely to face catastrophic health expenditures.

As expected, the number of employees in family decreases the chance of suffering from CHE. The negative coefficient and significance level $99 \%$ of this variable in the present study confirms this hypothesis, where in households with more number of employees in family, it is more likely for the households to suffer from CHE The odds ratio is equal to 0/70 i.e. households with only a employee and 0/66 i.e. more number of employees. This result is consistent with the 
studies conducted by (Pal, 2012; Hajizadeh and Nghiem, 2011; Mondal, 2010). One of the innovations of the present study (which is not observed in previous studies) was to consider the development index of the province of the place of residence of households in terms of access to healthcare providers as a factor affecting the probability of facing CHE. According to the results, households living in Iran's less developed provinces have been more exposed to CHE health.

With an increase in the number of educated people in a family, the likelihood of the household exposure to $\mathrm{CHE}$ decreases. Given the fact that literacy opportunity is higher in well-off families, and being literate provides more economic opportunities for the individual, literate people are also better off with lifestyles and avoiding high-risk behaviors. As a result, small households are more likely to face CHE. In contrast, Su et al. (2006) showed that the probability of $\mathrm{CHE}$ increase by five percent per person added to the household population. The results indicate that households living in mortgage or rental houses more likely suffer from $\mathrm{CHE}$ than those who own a home. The coefficient of this variable at the confidence level $99 \%$ was significant and negative. The odds ratio is equal to 0.92 , and because this ratio is less than one, it is interpreted that property ownership can be a household protecting variable against CHE. Ekman (2007) in his study showed that housing ownership is one of the barrier variables to household CHE healthcare exposure.

Insurance coverage has not reduced the likelihood of household exposure to $\mathrm{CHE}$. This variable was significant at $99 \%$ level and its odds ratio was 1.1, Although at the first glance, considering the mechanism of medical insurance (accumulation of risk), health insurance should be a factor in reducing the likelihood of a household to face $\mathrm{CHE}$, and given the rich literature available in this field, including the studies of Samkotra et al(2008). in Thailand, implementation of insurance policies and prepaid mechanisms is considered among the most important factors in protecting households against CHE(Limwattananon et al, 2008). However, limited studies such as the Ekman(2007), WagStaff and Lindlow(2008), Ghiasvand et al (2010), Nekoeimoghadam et al (2013) and O'donnell et al (2008) show that health insurance increases the risk of exposure to $\mathrm{CHE}$ for households by encouraging people to use more services as well as more advanced services. And for reasons such as:

1. Inefficiency of health insurance in terms of non-coverage of healthcare services in the sense of not defining suitable packages of services by insurance(Ekman, 2007)

2. Increased induction demand of household and consequently the increased in the share of health expenditure in the household budget(Wagstaff and Lindelow, 2008)

3. The inadequacy of the insurance coverage depth, that is, insurances cover a small share of service expenditure, and the burden of more health expenditure is placed on the shoulder of the household, which increases their risk of facing catastrophic expenditure; the study by Rezapur et al. (2016) conducted in Tehran, confirms the results of the present study(Arab at al, 2016).

Income deciles are a measure of the household's economic situation; the negative and significant effect on these models, at a $99 \%$ confidence level, on the probability suffering from $\mathrm{CHE}$, indicates that lower deciles more likely suffer from CHE than households in upper deciles. The results of Sue et al. (2006) and Ekman (2007) also confirm the results of this study.

This result is important in two respects: First, due to the lack of insurance efficiency and the high share of out of pocket payment, lower deciles are more exposed to $\mathrm{CHE}$ and second, the prevalence of illness is higher in lower deciles.

Based on the results, granting cash subsidies at a significant level $99 \%$ has increased the probability of facing CHE. And because the odds ratio of this variable is more than one, it is construed that subsidies to households cannot be a protective variable for the household against household exposure to catastrophic health expenditures. 
A clear picture of the effect of such a plan on the CHE of Iranian households is shown, such that these expenditures have fallen sharply since 2011, and continued in 2012. However, paying cash subsidies directly to bank accounts created a significant leap in the liquidity amount of the people. Based on economic courses, the inflation growth rate is one of the most reliable outcomes of liquidity growth. Although inflation in Iran was $10.13 \%$ in 2010 , it reached $20.62 \%$ in 2011 and reached $27.35 \%$ and 39.26\% in 2012 and 2013, respectively (based on World Bank data). Of course, inflation has been much worse for the health sector, and health sector inflation exceeded inflation in the entire economy. This situation had a quite devastating effect on the health sector in Iran. The CHE of the households exposed to these costs sharply raised since 2012, and even exceeded the pre-implementation of targeted subsidized. It can be judged that the implementation of this policy has had a negative effect on one of the most important sectors of household welfare, i.e. health.

HTP, a very costly project, has been criticized by many experts. As the budget of the plan is addressed to be 48000 billion Rials, which is believed that its financial burden is out of the power of the government. This plan has been implemented to support households against medical payments, but the changes and effects of other sectors, such as the economy, industry, etc., from which high inflation, increased poverty line, production stagnation, etc. can be named, have weakened the status of lower decile household so that the economic transformation plan has not succeeded even with its primary objective of improving the equity of financing health expenditures. The results of this study indicate that after the implementation of this plan, there has been no change in the status of Iranian households regarding the indices of justice in financing health sector, unless it has prevented the worsening of household health payments.

\section{Conclusion}

Future economics and healthcare reforms in Iran should not only focus on expanding the coverage, but also on improving the equity of distribution of healthcare benefits. Government should consider equitable distribution of subsidies, mainly among low-income citizens.

In order to prevent harm to the poor and to deteriorate the status of justice, the long-run inflationary effects of policies must be of serious concern to politicians. During TSP, relatively significant cash became available for households, thus improved the $\mathrm{CHE}$ and $\mathrm{FFCl}$ indices over a short term. But afterward, the harmful effects of the distribution of money and the growth of liquidity became apparent (even households began to receive several loans from banks with the support of this money), and inflation and poverty line increased sharply. The policy pursued by the government to reduce poverty resulted in rising inflation above $40 \%$ and poverty line has increased from $10,800,000$ Rials (\$257) to $\$$ $26,750,000$ Rials (\$636) in 2013. It also caused a sharp decline in the national currency value. The out of pocket payment was over 50\% between 2011 and 2013(WDI, 2018). So, although this plan was implemented to improve justice, there were no satisfactory results in the area of equity financing of the health sector, and we witnessed a high inflation years after the implementation of this plan, caused by the injection of liquidity into the community. Therefore, most likely there would be far better results if monthly cash payments for households were done as expanding insurance coverage.

Another important policy was the implementation of the costly plan of the health system transformation. Although the government claims that this plan has been successful, in the years after the implementation of this policy, we did not observe a significant change in the status of equity indices in health financing. One of the dimensions of inefficiency of government support policies is to ignore the social and economic characteristics of households in implementing plans to reduce their chances of facing $\mathrm{CHE}$.

The present study investigated the effect of other factors on the probability of exposure to CHE in the households, which can provide more reliable results than previous studies given the large sample size. The presence of elderly 
people (over 65 years of age) increases the risk of $\mathrm{CHE}$ in the household. Therefore, elderly empowerment policies, as well as the modification of their insurance coverage, can protect households with elderly against $\mathrm{CHE}$. One of the important issues in Iran's economy is the high cost of housing. The share of housing from household budget in Iran is much higher than in other countries. The reason for this is not the subject of the study, but households that are not homeowners, due to the high rental cost of housing in Iran, spend a large part of their budget on housing costs. So it's very likely that such households be faced with CHE. Supportive policies for renting households seem to be very effective in health expenditure and reducing the percent.

Finally, it can be stated that one of the most important means of protecting households against $\mathrm{CHE}$ is insurance coverage. Of course, insurance coverage in Iran has not been able to have such an effect, which is rooted in the inadequacy of insurance. Modifying the structure of insurance and improving its efficiency should be a top priority of the health sector. Also, according to the results, policymakers are recommended to take into account the households faced with $\mathrm{CHE}$, which based on this study, households with more elderly, low income, without private house, rural and resident in deprived provinces, to adopt supportive policies to improve equity in financing health expenditures so that they can better protect households against $\mathrm{CHE}$. Of course, the government has recently sought to eliminate the subsidies of more well-off people and support more families at risk. The results of this article can be useful for selecting target groups.

\section{Abbreviations}

TSP: targeted subsidy plan

HTTP: Health Transformation Plan

FFCl: Fairness in Financial Contribution

CHE: Catastrophic Health Expenditures

WHO: World Health Organization

NGO: non-government organization

MOHME: Ministry of Health and Medical Education

PHC: primary healthcare

OOP: out-of-pocket

SSO: Social Security Organization

AFMSO: Armed Forces Medical Service Organization

IHIO: Iran Health Insurance Organization

FFC: Fair financial contribution

HTTP: Health Transformation Plan

VAT: value-added tax 


\section{Declarations}

\section{Acknowledgements}

The authors would like to the Program and Budget Organization for providing data on household income and expenditure.

\section{Authors' contributions}

YM and JY conceptualized and designed the study, collected data and completed data analysis YM and AM drafted the initial manuscript. AM and HY revised the manuscript critically and participated in the study design. AK participated in study design and helped to draft the manuscript.

\section{Funding}

Not applicable

\section{Availability of data and materials}

The datasets generated and/or analyzed during the current study are available here:ttps://www.amar.org.ir/

\section{Ethics approval and consent to participate}

The study was approved by the Ethics Committee of Urmia University

\section{Consent for publication}

All authors read and approved the final version of the manuscript for publication.

\section{Competing interests}

The authors declare that they have no competing interests in this study.

\section{Author details}

${ }^{1}$ Department on Economics, Faculty of Economics and Management, Urmia University, Iran. Master student of Health Economics, ${ }^{3}$ Department of Health management \& Economics, School of Public Health, Tehran, Iran. ${ }^{3}$ Department of Health management \& Economics, School of Public Health, Tehran, Iran. ${ }^{4}$ Department of Health Economics.

Kermanshah University of Medical Sciences, Kermanshah, Iran. ${ }^{5}$ Department of Health Economics, Urmia. University of Medical Sciences, Iran

\section{References}

1. Arab M, Roodbari M, Rezapoor A. Catastrophic and impoverishing health expenditure in Tehran urban population. Journal of Health Administration. 2016;19(63):55-67.

2. Chen, M., Y. Zhao, and L. Si, Who pays for health care in China? The case of Heilongjiang Province. PLoS One, 2014. 9(10): p. e108867.

3. Ekman B. Catastrophic health payments and health insurance: Some counterintuitive evidence from one lowincome country. Health policy. 2007;83(2-3):304-13. 
4. Enami A, Lustig N, Taqdiri A. Fiscal policy, inequality, and poverty in Iran: assessing the impact and effectiveness of taxes and transfers. Middle East Development Journal. 2019;11(1):49-74.

5. Ghiasvand H, Hadian M, Maleki M, Shabaninejad H. Determinants of catastrophic medical payments in hospitals affiliated to Iran University of Medical Sciences 2009. Hakim Research Journal. 2010;13(3):145-54.

6. Group WB. World development report 2016: digital dividends: World Bank Publications; 2016.

7. Hajizadeh M, Nghiem HS. Out-of-pocket expenditures for hospital care in Iran: who is at risk of incurring catastrophic payments? International journal of health care finance and economics. 2011;11(4):267.

8. Kirby, M., The right to health fifty years on: still skeptical? Health and Human Rights, 1999: p. 6-25.

9. Leary, V.A., The right to health in international human rights law. Health and human rights, 1994: p. 24-56.

10. Limwattananon S, Tangcharoensathien V, Prakongsai P. Equity in financing healthcare: impact of universal access to healthcare in Thailand. 2008.

11. Ma X, Wang Z, Liu X. Progress on Catastrophic Health Expenditure in China: Evidence from China Family Panel Studies (CFPS) 2010 to 2016. International Journal of Environmental Research and Public Health. 2019;16(23):4775.

12. Merlis M, Gould D, Mahato B, Fund C. Rising out-of-pocket spending for medical care: a growing strain on family budgets: Citeseer; 2006.

13. Mohammad Mosadeghrad A. Patient choice of a hospital: implications for health policy and management. International journal of health care quality assurance. 2014;27(2):152-64.

14. Mondal S, Kanjilal B, Peters DH, Lucas H. Catastrophic out-of-pocket payment for health care and its impact on households: Experience from West Bengal, India. Future Health Systems, Innovations for equity. 2010.

15. Mosadeghrad AM. Factors influencing healthcare service quality. International journal of health policy and management. 2014;3(2):77.

16. Murray CJ, Knaul F, Ke X, Musgrove P, Kawabata K. Defining and measuring fairness in financial contribution to the health system. Murray CJL, Knaul F, Xu k, Musgrove P, Kawabata K(2000) Defining and Measuring Fairness of Financial Contribution World Health Organization GPE Discussion Paper Series. 2000(24).

17. Murray CJ, Xu K, Klavus J, Kawabata K, Hanvoravongchai P, Zeramdini R, et al. Assessing the distribution of household financial contributions to the health system: concepts and empirical application. Health systems performance assessment: debates, methods and empiricism Geneva: World Health Organization. 2003;12.

18. Naghdi S, Azami SR, Naghdi A, Faghi Solouk F, Ghiasvand H. The Inequity of Expenditure Ratios on Health and Food among Different Deciles of Iranian Households. 2013.

19. Nekoeimoghadam M, Akbari-Javar M, Amiresmaili M, Baneshi M, Ganjavai S. Households exposure to catastrophic health expenditures and the affecting factors in Kerman Province, Iran. Journal of Management And Medical Informatics School. 2013;1(2):101-90.

20. O'donnell O, Van Doorslaer E, Rannan-Eliya RP, Somanathan A, Adhikari SR, Akkazieva B, et al. Who pays for health care in Asia? Journal of health economics. 2008;27(2):460-75.

21. NIHR, https://www.nihr.ac.uk/ 2016

22. Organization WH. The world health report 2000: health systems: improving performance: World Health Organization; 2000.

23. Organization) WWH. https://www.who.int/gho/health_financing/out_of_pocket_spending/en/ 2015 [

24. Pal R. Analysing catastrophic OOP health expenditure in India: Concepts, determinants and policy implications. 2012.

Page $13 / 14$ 
25. Salehi-Isfahani D, Wilson Stucki B, Deutschmann J. The reform of energy subsidies in Iran: The role of cash transfers. Emerging markets finance and trade. 2015;51(6):1144-62.

26. Su TT, Kouyaté B, Flessa S. Catastrophic household expenditure for health care in a low-income society: a study from Nouna District, Burkina Faso. Bulletin of the World Health Organization. 2006;84:21-7.

27. Wagstaff A, Lindelow M. Can insurance increase financial risk?: The curious case of health insurance in China. Journal of health economics. 2008;27(4):990-1005.

28. WDI DataBase(2018). https://datacatalog.worldbank.org/dataset/wdi-database-archives

29. Wyszewianski L. Families with catastrophic health care expenditures. Health services research. 1986;21(5):617.

30. Xu K, Organization WH. Distribution of health payments and catastrophic expenditures methodology. Geneva: World Health Organization; 2005.

31. Xu, Ke, David B. Evans, Kei Kawabata, Riadh Zeramdini, Jan Klavus, and Christopher JL Murray. "Household catastrophic health expenditure: a multicountry analysis." The lancet 362, no. 9378 (2003): 111-117. 